All letters are subject to editing and may be shortened. General letters can be sent to bjgpdisciarcgp.org.uk (please include your postal address for publication), and letters responding directly to BJGP articles can be submitted online via eLetters. We regret we cannot notify authors regarding publication.

For submission instructions visit: bjgp.org/letters

\section{What tasks can physicians delegate to pharmacists?}

Many GPs believe that inclusion of allied health professionals in our general practice teams has been done through necessity rather than by choice due to difficulties in recruiting GPs.' Many practices lincluding my own) have demonstrated that our practice clinical pharmacists are not simply 'proxy GPs' but are highly skilled health professionals who perform many roles that are not appropriate for GPs to be performing. In this world of optimising resources and maximising 'Left Shift' lapologies for the blatant use of CCG-jargon) it has never been more important for the right person to be doing the right job, at the right time, in the right place, at the right rate.

\section{Carter Singh,}

GP Partner, Willowbrook Medical Practice, Sutton-in-Ashfield.

Email: drcartersinghagmail.com

\section{REFERENCE}

1. Yeung EYH, Mohammed RSD. What tasks can physicians delegate to pharmacists? Br J Gen Pract 2018; DOI: https://doi.org/10.3399/bjgp18X699509.

DOI: https://doi.org/10.3399/bjgp19X700649

\section{Huge hurdles for current returners and misdirected funding}

Significant barriers still exist for GPs trying to return from work abroad. ${ }^{1}$ Making an independent application to reapply to the MPL is racked with delays, not least because several private bodies need to be contracted in order to meet the requirements. It is exceedingly difficult to achieve this in under 3 months, meaning that returned GPs often exceed the 2-year cut-off period and are then required to go through the induction and refresher scheme, causing more delays. Even on an accelerated scheme, a GP is unlikely to be able to get back to unsupervised practice within 6 months of returning.

Funding bodies need to concentrate on streamlining the process for those who have already decided to return by, for example, creating a supportive body to help returning GPs with the MPL application. Hospital doctors have dedicated HR teams that are able to process compliance paperwork within days. If this system does not become more navigable and efficient there is a real risk that potential returning NHS GPs will either stay away or decamp to alternative specialty work. Online medical forums have already shown this to be happening.

\section{Sascha FJ Muldoon,}

Returning GP.

Email: sascha.muldoonddoctors.org.uk

\section{REFERENCE}

1. Tsukagoshi S, Caesar S, Weaver R, Merriel S.

Qualified GPs planning to work overseas: 'go, enjoy yourself, and come back'. Br J Gen Pract 2018. DOI: https://doi.org/10.3399/bjgp18X698621.

DOI: https://doi.org/10.3399/bjgp19X700697

\section{Treatment-resistant depression: consider autism}

Patients with treatment-resistant depression (TRD) are both interesting and challenging to manage.

It is easy to overlook other possible causes for TRD including autism, both diagnosed and undiagnosed. Autistic cognition differs from neurotypical cognition.

Autism can be difficult to identify in women, black and minority ethnic groups, older people, and individuals with diagnoses of attention deficit hyperactivity disorder, obsessive compulsive disorder, and learning disabilities. ${ }^{2,3}$

It is well recognised that autistic individuals are at significantly higher risk of diagnostic overshadowing. ${ }^{3,4}$ This typically manifests itself when a clinician informs an autistic individual with depression that their depressive symptoms are due to their autism, even though this attribution may be partially or completely inappropriate. Equally, the reverse can apply when an autistic individual is diagnosed with depression, when their autistic cognition would explain most of their symptoms.

It would be excellent if all trials, systematic reviews, and meta-analyses about TRD and associated topics were more explicit about how autism, both diagnosed and undiagnosed, and any associated diagnostic overshadowing are taken into consideration.

Clinicians need to be mindful of the possibility of undiagnosed autism in all patients with TRD, including those receiving cognitive behavioural therapy.

Michael J White,

GP, Hampshire.

Email: michael.white2anhs.net

\section{Competing interests}

Michael J White has an adult son with autism.

\section{REFERENCES}

1. Wiles N, Taylor A, Turner N, et al. Management of treatment-resistant depression in primary care: a mixed-methods study. Br J Gen Pract 2018. DOI: https://doi.org/10.3399/bjgp18X699053.

2. Royal College of General Practitioners. Autistic spectrum disorders toolkit. www.rcgp.org.uk clinical-and-research/resources/toolkits/asd-toolkit. aspx laccessed 5 Dec 2018).

3. Matson J, Williams LW. Differential diagnosis and comorbidity: distinguishing autism from other mental health issues. Neuropsychiatry 2013; 3(2): 233-243.

4. Joshi G, Petty C, Wozniak J, et al. The heavy burden of psychiatric comorbidity in youth with autism spectrum disorders: a large comparative study of a psychiatrically referred population. J Autism Dev Disord 2010; 40(11): 1361-1370.

DOI: https://doi.org/10.3399/bjgp19X700373

\section{Correction}

Research by Redmond NM et al, Impact of antibiotics for children presenting to general practice with cough on adverse outcomes: secondary analysis from a multicentre prospective cohort study. Br J Gen Pract 2018; DOI: https://doi.org/10.3399/bjgp18X698873, incorrectly mentioned odds ratio [OR] twice in the Results when describing Table 3, instead of risk ratio [RR]. This should have read: '(immediate risk ratio [RR] 0.82, $\mathrm{Cl}=0.65$ to 1.07; delayed RR $0.55, \mathrm{Cl}=0.34$ to 0.88 , overall $P=0.02)$.' The online version has been corrected.

DOI: https://doi.org/10.3399/bjgp19X700709 